\title{
ДОСЛІДЖЕННЯ РОЗПОДІЛУ ВТРАТ ЕНЕРГІЇ ЗА ЦИКЛОГРАМОЮ РОБОТИ СИСТЕМИ ГІДРОПРИВОДІВ
}

\author{
Левченко О.В. ${ }^{1}$ \\ ${ }^{1}$ Національний технічний університет України «Київський політехнічний інститут», Київ \\ Copyright (C) 2014 by author and the journal "Automation technological and business - processes". \\ This work is licensed under the Creative Commons Attribution International License (CC BY). \\ http://creativecommons.org/licenses/by/4.0/
}

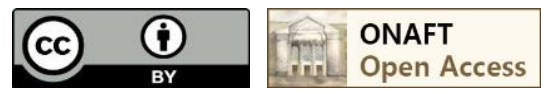

DOI: $10.15673 / 2312-3125$.

\begin{abstract}
Анотація
Досліджено практичні системи промислового гідроприводу з метою визначення величини та процесу формування енергетичних втрат за циклограмою та за терміном роботи системи. Встановлено три періоди роботи багатопривідної гідравлічної системи, які характеризуються сталим або змінним енергоспоживанням. Виявлено необхідність проведення досліджень впливу температурних режимів роботи системи, терміну виходу системи на режим теплового балансу, впливу факторів параметричної неузгоденості характеристик енергетичного і виконавчого рівнів.
\end{abstract}

\section{Abstract}

Practical industrial hydraulic drive system was studied to determine the size and formation process of energy losses using timeline and the term of the system. Three periods of hydraulic system with many devices were established, which characterized by constant or variable power consumption. Necessity of studies of the effect of temperature conditions of the system was defined, the achievement term of system on the heat balance mode, factors exposure of parametric mismatch characteristics of energy and executive levels.

Ключові слова

Енергетична ефективність, енергетичні втрати, робочий цикл, система гідроприводів.

Проблема та ії̈ зв'язок з науковими та практичними задачами.

Особливістю систем циклового об'ємного гідроприводу є наявність великої $(3 \div 50)$ кількості виконавчих та допоміжних пристроїв, що викликано наявністю великої кількості технологічних або експлуатаційних операцій 3 різними по величині зусиллями та швидкостями на приводах. Таким чином, ці системи складаються 3 приводів, які мають різну потужність та приводів однакової потужності, але які працюють на різних витратах та тисках. Визначення втрат енергії за відомими методиками спирається на три складові ККд (механічний, гідравлічний, об’ємний). В цикловій системі ці складові мають підпорядкування циклограмі та діям приводів. Крім того, процес визначення енергетичних втрат ускладнюється завдяки впливу факторів, які є типовими для багатопривідних систем: змінне навантаження на виконавчих пристроях в такті, одночасне спрацювання декількох приводів, зміна властивостей робочої рідини в процесі експлуатації, відхилення навантаження на приводі від номінального значення.

Аналіз літературних джерел [1-3] та практичних систем показав, що величина та процес формування енергетичних втрат багатопривідних циклових систем об'ємного гідроприводу є складним. На нього впливає значна кількість факторів, величина яких залежить від типу гідравлічного обладнання та режимів експлуатації 


\section{$\underline{1}$ ПИТАННЯ ТЕОРІЇ, МЕТОДИ ТА АЛГОРИТМИ ЕФЕКТИВНОГО АВТОМАТИЧНОГО УПРАВЛІННЯ ОБ’ЄКТАМИ ХІМІКО-ТЕХНОЛОГІЧНОГО ТИПУ}

системи. Для уточнення розрахунку повинні бути визначені фактори та оцінений їх вплив на формування дисипації енергії в системі.

Аналіз формування потоку дисипації енергії виконано по двом напрямкам:

- $\quad$ по рівням гідроапаратів в структурі системи,

- $\quad$ за циклограмою та за терміном роботи.

Використання цих напрямків дозволяє не просто врахувати втрати в гідроапаратах, а провести визначення рівня енергоспоживання системи за визначений проміжок часу роботи системи за допомогою розробки на їх основі узагальненої моделі для різних схемних рішень.

При аналізі втрат в гідроапаратах по рівням структури системи використано підхід німецької фірми Fеsto [4], який в порівнянні з іншими, дозволяє проводити розподіл апаратів за їх функціональним призначенням. Розподіл по рівням гідроапаратів дозволяє проводити порівняння класу систем. За допомогою такого підходу може бути реалізоване прогнозування рівня енергоспоживання типових схемних рішень на етапі до початку проектування, коли невідома схема підключення гідроапаратів в системі.

Аналіз виконано на прикладах циклових систем об’ємного гідроприводу встановленої потужності, що перевищує 50 кВт:

- кувального маніпулятора МК30 Новокраматорського машинобудівного заводу «НКМЗ» (потужність 483 кВт);

- ливарної машини ДП-10 доменної печі Дніпродзержинського металургійного комбінату ім. Дзержинського «ДМКД» (потужність 874 кВт);

- $\quad$ автоматизованого пресу для калібрування труб D125/150 фірми Demag Нікопольського південнотрубного заводу «НПТЗ» (потужність 2560 кВт);

- автоматизованого пресу для пресування целюлози ВР-10000 фірми Bosch Rexroth (потужність 213 кВт).

Для обраних прикладів промислових систем є характерним наявність великої кількості виконавчих пристроїв (більше 10), достатньо складний робочий цикл (автоматичні системи 3 наявністю паралельних та альтернативних операцій - 4-го та 5-го класу складності та наявність одночасних спрацювань декількох виконавчих пристрої), змінні навантаження (крутні моменти) та лінійні (кутові) швидкості виконавчих пристроїв, а відповідно і змінні навантаження при спрацюванні приводів.

Дослідження виникнення енергетичних втрат в систем гідроприводів по рівням гідроапаратів в структурі системи виконано в роботах [2, 3], тому зосередимо свою увагу на другому напрямку формування дисипації енергії, а саме за циклограмою роботи системи.

Викладення матеріалу та результати.

До другого напрямку виникнення дисипації енергії відповідно відносяться втрати за терміном роботи та за циклограмою системи.

Аналіз енергоспоживання за терміном роботи та за циклограмою системи спрямовано на можливість використання середньоциклових енергетичних показників. В існуючих методиках [5, 6] рівень енергоспоживання визначається складанням добутків середньоциклової потужності на час роботи кожного привода системи та втрат в гідроапаратах і по довжині трубопроводів:

$$
E_{3}=\sum_{1}^{n} \frac{N_{i} \cdot t}{\eta_{i}}+\Delta E=\sum_{1}^{n} \frac{F_{i} \cdot\left(M_{i}\right) \cdot v_{i} \cdot\left(\omega_{i}\right) \cdot t}{\eta_{i}}+\Delta E,
$$

де $N_{n p}$ - середньоциклова потужність привода, Вт,

$\eta_{i}$ - повний ККД привода, \%,

$\Delta E-$ втрати в гідроапаратах та по довжині трубопроводів, Вт·с,

$F_{i} \cdot\left(M_{i}\right)$ - зусилля (крутний момент) виконавчого пристрою, Н (Н·м),

$v_{i} \cdot\left(\omega_{i}\right)$ - лінійна (кутова) швидкість виконавчого пристрою, м/с (рад/с),

$n$ - кількість приводів системи, шт,

$t$ - тривалість такту, с.

Дослідження роботи практичних багатопривідних систем показало, що загальний час роботи системи можна розбити на три періоди, які характеризуються сталим або змінним енергоспоживанням: початковий період, період 


\section{$\underline{1}$ ПИТАННЯ ТЕОРІЇ, МЕТОДИ ТА АЛГОРИТМИ ЕФЕКТИВНОГО АВТОМАТИЧНОГО УПРАВЛІННЯ ОБ’ЄКТАМИ ХІМІКО-ТЕХНОЛОГІЧНОГО ТИПУ}

стабільної роботи та заключний період (рис. 1). Ці періоди характеризуються різними причинами виникнення енергетичних втрат в системі.

$$
T_{\text {зАГ }}=T_{\Pi \Pi \Pi}+T_{C P}+T_{3 \Pi}=T_{Ц} \cdot K_{\Pi I \Pi}+T_{Ц} \cdot K_{C P}+T_{Ц} \cdot K_{3 \Pi},
$$

де $T_{\text {ПII }}$ - тривалість початкового періоду, с,

$T_{C P}$ - тривалість періоду стабільної роботи, с,

$T_{3 \Pi}$ - тривалість заключного періоду, с,

$T_{L}$ - тривалість одиничного циклу, с,

$K_{\text {ПII }}, K_{C P}, K_{3 П}$ - кількість одиничних циклів в початковому періоді, періоді стабільної роботи та заключному періоді.

Початковий період роботи системи характеризується зміною рівня енергоспоживання до моменту виходу системи на режим теплового балансу. Він може бути розділений на дві частини, для яких характерна різна швидкість зміни рівня енергоспоживання.

$$
T_{\text {ПII }}=T_{\text {ППІ I }}+T_{\text {ПII II }},
$$

Перша частина початкового періоду роботи системи $T_{\text {ПпI }}$ характеризується зростанням енергоспоживання за рахунок включення корисного навантаження на виконавчих пристроях. Тривалість цієї частини початкового періоду незначна і дорівнює тривалості від одного до п’яти одиничних циклів роботи системи, в залежності від складності системи і тривалості одиничного циклу.

$$
T_{\text {ПІІ I }}=(3 \div 5) \cdot T_{Ц},
$$

В другій частині $T_{\text {пп II }}$ відбувається повільна зміна рівня енергоспоживання, i має різну тривалість в залежності від потужності системи, нерівномірності навантаження на виконавчих пристроях. Друга частина початкового періоду проходить 3 циклічним навантаженням на виконавчих пристроях і триває до моменту настання режиму теплового балансу в системі. Для промислових систем, які розглядались, тривалість другої частини може складати від 2 до 55\% загального часу роботи системи. Загалом тривалість початкового періоду в залежності від різних факторів, в тому числі й від нерівномірності навантаження на виконавчих пристроях, може сягати 70\% від загальної тривалості робочої зміни.

Період стабільної роботи системи характеризується зміною енергоспоживання системи за циклограмою роботи виконавчих приводів.

Заключний період роботи системи характеризується збільшенням рівня енергетичних втрат за рахунок зменшення корисних навантажень на виконавчих пристроях при сталій затраченій потужності та за рахунок сповільнення роботи машини.

На всіх трьох етапах дисипація енергії припадає, в першу чергу, на місцеві опори в гідроапаратах та втрати в гідравлічних магістралях, з тією відмінністю, що на етапі стабільної роботи системи ці втрати можуть бути замінені середньоцикловими, так як температура і в'язкість робочої рідини залишаються в певному діапазоні.

Дослідження показали, що додатковою причиною виникнення дисипації енергії є взаємний вплив роботи декількох виконавчих пристроїв [6]. Як було встановлено раніше, енергетичний потік пройшовши ряд перетворень та апаратів системи трансформується в корисну роботу, яка виражається певним зусиллям та швидкістю робочого органу приводу (для гідроциліндра) і крутним моментом та частотою обертання валу (для гідромотора).

В кожному такті за циклограмою роботи системи траєкторія енергетичного потоку змінюється по напрямку і по кількості розгалужень. Це викликано тією обставиною, що в кожному такті в процесі роботи спрацьовують різні виконавчі пристрої та змінюється кількість приводів, які одночасно спрацьовують.

$$
E=\int_{i=0}^{t}\left(\sum_{j=1}^{n} F_{j} \cdot v_{j}+\sum_{j=1}^{n} M_{j} \cdot \omega_{j}\right) \cdot d t+\int_{i=0}^{z} \Delta N(s, t, T) \cdot d t .
$$

Проведений аналіз показав, що сумарна потужність багатопривідної системи в певні моменти не відповідає алгебраїчній сумі потужностей приводів. Порівняння рівня енергоспоживання промислових систем показало, що як правило 30-80\% виконавчих пристроїв системи мають різні експлуатаційні характеристики при використанні одного джерела гідравлічної енергії. Таким чином дисипація енергії за циклограмою роботи системи може виникати також за рахунок неузгодженості параметрів виконавчих пристроїв системи, тобто тиску та витрати, та за рахунок енергетичної неузгодженості в залежності від обраного схемного рішення. 


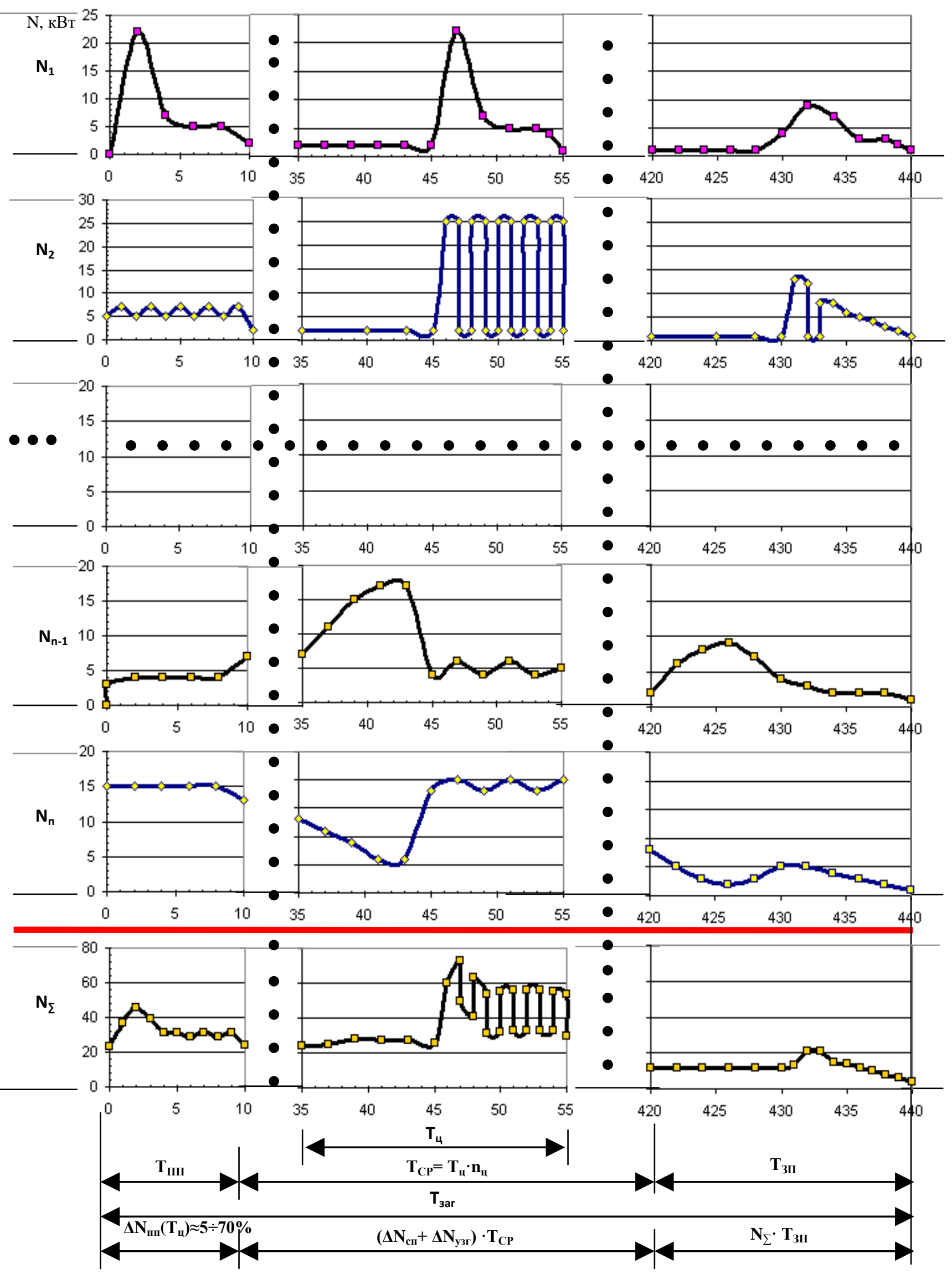

Рис. 1 - Формування втрат енергії циклового гідроприводу в часі: $\mathrm{N}_{1}, \mathrm{~N}_{2}, \mathrm{~N}_{\mathrm{n}-1}, \mathrm{~N}_{\mathrm{n}}, \mathrm{N}_{\Sigma}-$ потужність, 1, 2, n-1, n - порядковий номер виконавчого пристрою 


\section{1 ПИТАННЯ ТЕОРІЇ, МЕТОДИ ТА АЛГОРИТМИ ЕФЕКТИВНОГО АВТОМАТИЧНОГО УПРАВЛІННЯ ОБ’ЄКТАМИ ХІМІКО-ТЕХНОЛОГІЧНОГО ТИПУ}

Для побудови уточненої моделі, яка дозволяє прогнозувати енергетичні характеристики системи за ії схемним рішенням, необхідно провести додаткові експериментальні дослідження, зокрема, дослідження впливу температурних режимів роботи системи, терміну виходу системи на режим теплового балансу, впливу факторів параметричної неузгодженості характеристик енергетичного і виконавчого рівнів.

Схеми систем, які мають однакові експлуатаційний цикл та характеристики виконавчих пристроїв, як правило, відрізняються реалізацією енергетичного рівня системи та пристроями узгодження з виконавчим рівнем (наприклад, використання розвантаження насосного агрегату, застосування пропорційної керуючої апаратури тощо).

При розробці схемних рішень найбільш поширені такі способи зменшення енергоспоживання систем гідроприводу: розвантаження насосного агрегату через розподільник; розвантаження насосного агрегату 3 утриманням у гідромагістралі сталого тиску; використання регульованих насосів; рекуперація енергії силового привода в замкнутих гідросистемах; повна теплова рекуперація втраченої теплової енергії; встановлення паралельно підвідним лініям гідроциліндра ліній зі зворотними клапанами, які з’єднують напірну та зливну лінії при переході відповідних штуцерів поршнем та ін.

Рівень енергетичної ефективності, а власне величина енергетичних втрат визначається споживаною потужністю системи. Таким чином схемна реалізація енергетичного рівня залежить від реальних значень тиску та витрати при заданих експлуатаційних навантаженнях на виконавчих пристроях системи. Тобто енергетичний рівень системи може бути запропонований у вигляді 4-х основних типів та їх модифікацій:

- Система з постійним тиском та постійною витратою - система 3 нерегульованим насосом та переливним клапаном, тиск і витрата робочої рідини постійні ( $p$-const, $Q$-const $)$;

- Система зі змінним тиском та постійною витратою - система з нерегульованим насосом та пропорційним переливним клапаном, система 3 нерегульованим насосом та 2 і більше переливними клапанами, налаштованими на різні тиски, система 3 нерегульованим насосом та мультиплікаторами або демультиплікаторами, тиск змінний, витрата робочої рідини постійна $(p-\mathrm{var}, Q-$ const) ;

- Система з постійним тиском та змінною витратою - система з регульованим насосом з регуляторами тиску, витрати, потужності, з заданим та дистанційним керуванням, тиск постійний, витрата робочої рідини змінна ( $p$-const, $Q$-var);

- Система зі змінним тиском та змінною витратою - системи 3 регульованим насосом 3 різними регуляторами та пропорційним переливним клапаном, системи з двома і більше насосами, тиск і витрата робочої рідини змінні $(p-v a r, Q-v a r)$.

Таким чином, відповідно до структури системи по рівням гідроапаратів, схемні рішення, для реалізації однієї експлуатаційної задачі, відрізняються апаратами енергетичного (джерела гідравлічної енергії) та керуючого (апарати узгодження параметрів системи) рівнів і утворюють 4 основні класи гідравлічних систем, методики розрахунку і визначення рівня енергоспоживання яких мають свої особливості.

Оскільки дисипація енергії є наслідком втрат потужності, з одного боку, та часу цих втрат, з іншого, ії можна розглядати як інтегральну функцію підпорядковану циклограмі роботи системи:

$$
\int_{i=0}^{x} \Delta N \cdot d t=\int_{i=0}^{x} P \cdot Q \cdot d t-\int_{i=0}^{x}\left(\sum_{j=1}^{n} F_{j} \cdot v_{j}+\sum_{j=1}^{n} M_{j} \cdot \omega_{j}\right) \cdot d t .
$$

Таким чином траєкторія енергетичного потоку змінюється не лише за напрямком та кількістю розгалужень, а й змінюється потужність потоку на різних етапах роботи багатопривідної системи $\left(\mathrm{T}_{\Pi п}, \mathrm{~T}_{\mathrm{CP}}, \mathrm{T}_{3 п}\right)$. Викладені вище умови вказують на неможливість використання типового інженерного розрахунку за середніми значеннями чи за встановленою і потужністю і ККД при визначенні рівня енергоспоживання системи та необхідність проведення експериментальних досліджень по визначенню впливу одночасної роботи виконавчих пристроїв, температури робочої рідини, нерівномірності навантаження в такті та в циклі та необхідністю моделювання іiі роботи за циклограмою та за типом схемного рішення.

Висновки: Проаналізовано роботу практичних систем та встановлено напрямки виникнення втрат в тривалості роботи та за циклограмою. Визначено типові для багатопривідних систем фактори роботи, які спричиняють енергетичні втрати в процесі експлуатації. Встановлено, що енергетичні втрати системи залежать не лише від 


\section{$\underline{1}$ ПИТАННЯ ТЕОРІЇ, МЕТОДИ ТА АЛГОРИТМИ ЕФЕКТИВНОГО АВТОМАТИЧНОГО УПРАВЛІННЯ ОБ’ЄКТАМИ ХІМІКО-ТЕХНОЛОГІЧНОГО ТИПУ}

характеристик гідравлічних апаратів, а й від режимів роботи системи і можуть змінюватись на різних часових інтервалах роботи системи. Запропоновано реалізацію енергетичного рівня багатопривідної гідравлічної системи у вигляді 4-х основних типів та їх модифікацій, в залежності від можливості зміни тиску і витрати робочої рідини в процесі експлуатації. Визначено напрямки додаткових експериментальних досліджень, зокрема, дослідження впливу температурних режимів роботи системи, терміну виходу системи на режим теплового балансу, впливу факторів параметричної неузгодженості характеристик енергетичного і виконавчого рівнів.

Література

1. Яхно О.М. Повышение эффективности использования энергии в гидравлических механизмах сельскохозяйственных машин / О.М. Яхно, С.И. Пастушенко // Всеукраїнський науково-технічний журнал “Промислова гідравліка і пневматика". - 2004. - Вип. 3. - С. 92-98;

2. Левченко О.В. Підвищення ефективності роботи систем гідроприводів циклічної дії / О.В. Левченко // В кн.: Вісник Національного технічного університету України («КПІ») Серія машинобудування. - 2012. Вип. 65. - С. 125-130;

3. Левченко О.В. Особливості оцінки ефективності багатопривідної гідравлічної системи / О.В. Левченко // Наукові праці ДНТУ. Серія: "Гірничо-електромеханічна". - 2012. - Вип. 2(24). - С. 142-149;

4. Ebel F., von Terzi M. Festo Didactic. Mechatronics.: Festo Didactic GmbH\&Co., D73770 Denkendorf, 2000.$108 \mathrm{~S}$;

5. Колот О.В. Методика і результати експериментального визначення випадкових змін дисипативних параметрів гідропривода // Вестник НТУУ «КПИ». Машиностроение, К.:2004, №45. С. 117-120;

6. Введение в механотронику: Учеб. Пособие для студ. спец. «Гидравл. и пневмат. машины», «Прикладная механика», «Инженерная механика» / О.М. Яхно, А.В. Узунов, А.Ф. Луговской и др. - К.: НТУУ «КПИ», 2008. $-528 \mathrm{c}$.

References

1. Yahno O.M. Povyishenie effektivnosti ispolzovaniya energii $\mathrm{v}$ gidravlicheskih mehanizmah selskohozyaystvennyih mashin / O.M. Yahno, S.I. Pastushenko // Vseukrayinskiy naukovo-tehnIchniy zhurnal "Promislova gidravlika i pnevmatika". - 2004. - Vip. 3. - S. 92-98;

2. Levchenko O.V. Pidvischennya efektivnosti roboti sistem gidroprivodiv tsiklichnoyi diyi / O.V. Levchenko // V kn.: Visnik Natsionalnogo tehnichnogo universitetu Ukrayini («KPI») Seriya mashinobuduvannya. - 2012. - Vip. 65. - S. 125-130;

3. Levchenko O.V. Osoblivosti otsinki efektivnosti bagatoprividnoyi gidravlichnoyi sistemi / O.V. Levchenko // Naukovi pratsi DNTU. Seriya: "Girnicho-elektromehanichna". - 2012. - Vip. 2(24). - S. 142-149.

4. Ebel F., von Terzi M. Festo Didactic. Mechatronics.: Festo Didactic GmbH\&Co.,D73770 Denkendorf,2000.-108S;

5. Kolot O.V. Metodika i rezultati eksperimentalnogo viznachennya vipadkovih zmIn disipativnih parametriv gidroprivoda // Vestnik NTUU «KPI». Mashinostroenie, K.:2004, \#45. S. 117-120;

6. Vvedenie v mehanotroniku: Ucheb. Posobie dlya stud. spets. «Gidravl. i pnevmat. mashinyi», «Prikladnaya mehanika», «Inzhenernaya mehanika» / O.M. Yahno, A.V. Uzunov, A.F. Lugovskoy i dr. - K.: NTUU «KPI», 2008. -528 s.

\section{НОВОСТИ АВТОМАТИЗАЦИИ}

\section{Рынок коммерческих беспилотников вырастет на 109\% к 2020 году}

Markets and Markets, исследовательская фирма из Далласа, Техас, выпустила 189-страничный отчет с прогнозами роста коммерческих дронов на мировом рынке со среднегодовыми темпами роста в сложных процентах (CAGR) 109,3\% и суммой в \$ 1,27 млрд в 2020 году, - сообщает Robotics.ua. В другом недавнем докладе исследования в IDTechEx оценки с Markets and Markets практически совпадают: электрические дроны: рынок беспилотных летательных аппаратов (БПЛА) 2015-2025 достигнет \$ 4,5 млрд к 2025 году.

(http://robotics.ua/news) 